\title{
"De vaquitas locas y profesores distraidos": modelos de televisión infantil y música en los programas televisivos chilenos Masamigos y Cachureos en la década del ochenta
}

\author{
"Of crazy little cows and distracted teachers": \\ models of television for children and Music in Chilean \\ children's TV shows Masamigos and Cachureos \\ in the 80 s decade
}

\author{
por \\ Francisca Meza Bernstein \\ University College, London, Inglaterra. \\ franciscamezab@gmail.com
}

\begin{abstract}
La televisión en Chile experimentó un cambio sustancial en 1975. La puesta en vigencia de una ley que impulsaba su total privatización implicó varios cambios, incluyendo una transformación de sus objetivos principales. La educación era el objetivo más relevante para la televisión pública antes de 1975, cambiando luego al entretenimiento. Una de las consecuencias de estas transformaciones fue la coexistencia de distintos modelos de televisión durante la década de 1980 en Chile. Estos modelos, a su vez, tuvieron un profundo impacto en la manera en que se desarrolló la televisión infantil en nuestro país. Este artículo explora la relación entre estos modelos televisivos y las músicas compuestas para programas de televisión, sugiriendo que las transformaciones de los primeros pudieron haber propulsado cambios en las segundas. Para este fin se analizaron dos emblemáticos programas de televisión infantil hechos en Chile durante la década de 1980: Masamigos (1983-1985) y Cachureos (1983-2008).

Palabras clave: Música infantil, televisión, programas de televisión infantil, Mazapán, Cachureos.
\end{abstract}

Television in Chile experienced a substantial change in 1975. The enactment of a law that promoted its total privatization implied several changes, including a transformation of its main purposes. Education was the most relevant aim for public television before 1975, then shifting to entertainment. One of the consequences of these transformations, was the coexistance of different television models during the 1980's in Chile. These models, in turn, had a deep impact on the way TV for children was made in our country. This article explores the relation between these TV models and the music composed for TV shows, suggesting that transformations in the former might have brought changes for the latter. For this purpose, two emblematic TV shows for children made in Chile during the 1980's were analysed: Masamigos (1983-1985) and Cachureos (1983-2008).

Keywords: Children's music, TV shows, Mazapán, Cachureos.

Cuncunas amarillas, pequeños muñecos que caben en la palma de la mano, cafeteras voladoras, buzones y lápices con extremidades, payasos y títeres: la fauna que habitó los programas de TV infantil en Chile durante los años setenta y ochenta fue vasta y variopinta, así como 
las músicas que la acompañaron. El presente texto busca ser una primera exploración en este mundo heterogéneo y disímil que, sin embargo, es indiferenciadamente denominado "música infantil", un rótulo homogeneizante y bajo el que se pierde la miríada de manifestaciones particulares que conforman este universo de música dedicada a los niños.

La música infantil parece ser un tema poco explorado en Chile. El material disponible corresponde en gran medida a trabajos de recopilación o enfocados en los aspectos pedagógicos de la música para niños. Los primeros son fundamentalmente compilaciones de música infantil tradicional, esto es, canciones difundidas y practicadas mediante la oralidad, de autor anónimo y cuyo origen en el tiempo es incierto ${ }^{1}$. Estas compilaciones no problematizan sobre el repertorio que difunden, sino que están hechas con un propósito más bien museístico, si se quiere; en la línea de lo que Amanda Minks² identifica como métodos inspirados en el paradigma difusionista dentro de los estudios etnomusicológicos de la infancia.

Como se anunciara anteriormente, también encontramos libros que recopilan o bien proponen repertorio desde el ámbito de la pedagogía ${ }^{3}$. Pero esta disciplina no solo se ha preocupado de la recopilación y creación de material didáctico, sino que también se ha encargado de reflexionar acerca de la música infantil, poniendo su énfasis en el cuestionamiento, transformación o perfeccionamiento de elementos ligados a la enseñanza y el aprendizaje musical. Ejemplos de esto son los trabajos de Dalcroze, Orff, Kodály, Suzuki, Self y Schafer, entre otros 4 .

La musicología chilena, en tanto, no se ha hecho cargo de las problemáticas respecto de música infantil desde su especificidad disciplinar, a excepción de algunos trabajos aislados, como "Infancia y televisión en los ochenta. Reflexiones a partir de la relevancia de Mazapán en el imaginario de la nostalgia", de Juan Carlos Poveda 5 . En vista de esta escasez de trabajos concernientes a música infantil en Chile abordados desde la musicología, considero que se requieren aportes actuales y disciplinarios de este tema, que planteen problemáticas que se deslinden del ámbito de lo netamente educativo, de modo de ampliar y diversificar las perspectivas desde las que nos aproximamos al mismo.

Durante la década de 1960 se produjo un hecho que cambiaría tanto los hábitos de entretención de los niños como su relación con la música: la llegada de la televisión. El aumento en el acceso a la TV durante los setenta y, luego, la franca explosión en la adquisición de este bien en los hogares chilenos durante los ochenta, permitieron un aumento notable en la difusión de música para niños en los programas de TV infantiles. Durante esta década también se produjeron importantes cambios en la forma de hacer televisión en nuestro país. Estas transformaciones propiciaron el surgimiento de una televisión infantil de carácter comercial -tras más de una década de desarrollo de un perfil predominantemente educativo- cuya propuesta se centró principalmente en el entretenimiento, y estuvo notoriamente marcada por la presencia de publicidad dentro de los programas. La parrilla programática infantil se nutrió principalmente de la emisión de una gran cantidad de dibujos animados importados, pero a pesar de ello, los canales de televisión contaban con al menos un programa de factura nacional dedicado a los niños.

Así, por ejemplo, en 1987, Televisión Nacional emitía Cachureos (1983-2008) y la señal de la Universidad Católica hacía lo propio con El mundo del Profesor Rossa (1981-2001); Canal 9

1 Pérez Ortega 1974; Díaz y Piracés 1983.

2002.

3 Kock 1977; Donaire y Paredes 1989.

4 Gaínza 2003.

5 2013. Se trata de una ponencia presentada en el VII Congreso Chileno de Musicología y cuyo texto no se encuentra disponible. 
exhibía repeticiones de Masamigos (1983-1985), en tanto la señal de la Universidad de Chile emitía Patio Plum (1985-1988). Finalmente, la Universidad Católica de Valparaíso cumplía con la programación infantil con su producción Pipiripao (1984-1996).

Si efectivamente "todo cambio en las formas de comunicación de una forma artística conlleva transformaciones en el orden formal de lo estético y de su construcción de sentido" 6 , sostengo como hipótesis que los cambios en el carácter y los objetivos de la televisión para niños hecha en Chile durante la década de 1980 -y la consiguiente coexistencia de dos modelos televisivos (educativo y comercial)- incidieron en el tipo de música que para los programas se compuso, tanto a nivel de los géneros musicales utilizados como al uso de la voz e instrumentación, entre otros. De este modo, se conformaron estéticas musicales con marcadas diferencias entre ellas, pero que sin embargo parecen haber mantenido puntos de contacto. Atendiendo al repertorio en estudio, considero que estas propuestas apelaron a modelos divergentes en el modo de entender la creación musical para niños, en los que se observa una tensión entre los conceptos de arte y educación, por una parte, y los de entretenimiento y mercado, por otra.

El objetivo general del presente trabajo consiste en realizar una primera aproximación con el propósito de identificar las características estilísticas de la música emitida por medio de programas de televisión infantil durante la década de 1980 en Chile, de modo de establecer las diferencias y semejanzas entre aquella compuesta para los programas de índole educativa y para aquellos de corte comercial, al tiempo de develar el carácter heterogéneo de la música infantil televisada durante este período en Chile. Además, me propongo descubrir las motivaciones creativas desde donde surgen estos programas, en busca de relaciones entre estas y las músicas que transmiten; para finalmente sugerir vínculos entre los cambios estructurales que se produjeron en la televisión chilena y las propuestas musicales de los programas estudiados.

Para la consecución de estos objetivos realizaré un análisis de la música de dos programas infantiles paradigmáticos emitidos durante la década de los ochenta, Masamigos y Cachureos. Como metodología de análisis utilizaré las propuestas de Rubén López Cano acerca de intertextualidad en música, complementándolas con las de Martín Azar.

\section{ACLARACIONES CONCEPTUALES}

Ahora bien, ¿a qué nos referimos cuando hablamos de música infantil? Por la ambigüedad del término, me veo en la necesidad de hacer algunas aclaraciones conceptuales operativas.

Encontramos en diversos textos pedagógicos el término "música infantil"7, mencionado como un género musical independiente. Sin embargo, no se ofrece una definición del mismo. Se señalan dentro de esta categoría ejemplos como Charo Cofré, Mazapán, Tikitiklip y música de películas, entre otros; los que no tienen en común más que el hecho de dirigirse al mismo grupo etario, ya que estilísticamente no parecen adscribir necesariamente a una línea común.

La prensa, por su parte, también prefiere esta denominación ${ }^{8}$ al anunciar conciertos $\mathrm{y}$ actividades realizadas por agrupaciones que se autodefinen en sus propias páginas web

6 Ochoa 2003: 22.

7 Ministerio de Educación 2011 y 2012.

8 "Disco de música infantil reúne a integrantes de Banda Conmoción y La Gallera", Diario Uchile (13 de agosto 2013); Carmen Gloria Benavides, "Primer encuentro de música infantil Panguipulli", Sonido Nacional (1 de octubre, 2014); Rodrigo Chacón, "Música infantil, tropical y el humor aseguran presencia [en] el Festival de Olmué 2015 (16 de octubre, 2014). 
oficiales ${ }^{9}$ como "música infantil" (e.g. Zapallo), o bien, como "música para pequeños y grandes" (e.g. Don Barbarroja), o incluso, aquellas que no hacen distinción expresa de edad objetiva, pero su puesta en escena está principalmente dirigida a los niños (e.g. Piececitos).

Finalmente, en la terminología adoptada por la bibliografía académica se prefiere la terminología "canción tradicional infantil" para referirse a música infantil de corte tradicional. Por ejemplo, Martín ${ }^{10}$, entiende por canciones infantiles "tanto las que se cantan a los niños [...] como las que los niños crean y recrean asociándolas a sus juegos y experiencias vitales...". Vélez ${ }^{11}$, en tanto, señala que "canción infantil" se refiere a "aquellas expresiones musicales de la tradición oral apropiadas y representadas por los niños, sin que esto quiera decir que fueron hechas para y/o por ellos". Y finalmente Watson ${ }^{12}$ apunta que la canción infantil tradicional sería "aquella composición poético-musical que el pueblo conoce, generalmente, por transmisión oral espontánea. No es obra de autor, por lo cual admite variaciones en música y letra...”.

En cuanto a la bibliografía en lengua inglesa, Adachi y Trehub ${ }^{13}$ utilizan el término children's songs (canciones infantiles o canciones para niños) como parte de un estudio pertinente a la decodificación emocional de música en niños, pero no otorgan una definición del mismo. Amanda Minks ${ }^{14}$, por su parte, propone reemplazar children's songs por expressive practices (prácticas expresivas), las que agruparían tanto prácticas musicales como poéticas y kinéticas. Mediante esta modificación terminológica pretende establecer una diferencia entre los estudios basados en la recolección y compilación de textos musicales y verbales, y aquellos cuyo centro de atención está en la interacción comunicativa que conecta la expresión de los niños con materiales concretos y sus contextos sociales.

En cuanto a los artículos académicos que abordan la música infantil desde la perspectiva de la industria musical, Tyler Bickford ${ }^{15}$ en su entrada "Children's music" del Grove Music Online, entrega la que me parece la especificación más apropiada al propósito de este trabajo cuando señala que:

"La historia de la producción y comercialización de grabaciones musicales dirigidas a niños, se caracteriza por una tensión entre los objetivos de educación y entretenimiento, así como por el rol de guardianes o curadores que las compañías disqueras, los padres y los educadores han jugado en la definición sobre cuál es la música "apropiada" para los niños. Desde sus inicios, la música comercial para niños se ha destacado por su integración de lo visual, lo narrativo y la inclusión de material en juguetes, películas, libros, y más tarde, en shows de televisión y multimedia" 16 .

9 www.zapallo.scd.cl; www.donbarbarroja.cl; www.piececitosenconcierto.wordpress.cl

10 2001: 59 .

11 2013: 44.

12 2011: 1 .

132000 .

142002 .

15 2011: 1 .

16 Traducción propia del original: "The history of producing and marketing commercial music recordings to children can be characterized by a tension between goals of education and entertainment, with record companies, parents, and educators playing important roles as gatekeepers and curators of "appropriate" music for children. From the beginning, commercial music for children has been notable for its integration with visual, narrative, and material media in toys, books, film, and, later, in television shows and multimedia”. 
Es esta tensión entre educación y entretenimiento, y la integración casi indisoluble con el campo de la visualidad, lo que caracteriza no tanto a la música infantil en general, como a la industria de la música infantil, es decir, a aquella música que forma parte de un mercado musical que edita y vende grabaciones, emite programas de televisión y promueve la presentación en vivo de sus artistas. Es a esta esfera a la que pertenecen los ejemplos que abordaré en esta comunicación. Es importante mencionar que el énfasis del presente trabajo está puesto en la producción de música difundida por medio de la industria televisiva y discográfica para un público infantil de aproximadamente 2 a 13 años, no así en la recepción ni en la apropiación de esta por parte de los niños (lo que dicho sea de paso resultaría altamente relevante de ser investigado). Es por ello que he preferido utilizar indistintamente los términos "música infantil” y "música para niños" en concordancia con el modo en que las fuentes bibliográficas lo hacen, y particularmente, la última que he referido.

\section{TRANSFORMACIONES EN LA TELEVISIÓN CHILENA DURANTE LAS DÉCADAS DE 1970 Y 1980 Y SU INCIDENCIA EN LA PROGRAMACIÓN INFANTIL}

Si bien la televisión comenzó a formar parte de los hogares chilenos a partir de la década de 1960, no fue hasta 1970 que se produjo la primera gran explosión en la adquisición de dicho bien. Según Jorge y Gonzalo Rojas 17 "se calcula que en 1965 había 50 mil unidades, y cinco años más tarde, en 1970, la cifra se había multiplicado por diez, alcanzando los 500 mil aparatos". No obstante, el incremento en la compra de aparatos televisivos no se detuvo ahí, y en 1983 "la cifra ya se elevaba a 3,5 millones de unidades, es decir, en promedio, había un televisor cada tres habitantes". Este cuantioso aumento se explica fundamentalmente por la política de apertura económica propulsada por la dictadura militar, que abarató considerablemente el precio del dólar, haciendo del televisor un bien accesible para gran parte de la población. Por otra parte, la cobertura de la red televisiva también experimentó una expansión considerable durante estas décadas. Ya en 1975 Televisión Nacional de Chile contaba con $90 \%$ de cobertura a nivel nacional, en tanto el canal de la Universidad Católica cubría potencialmente al $70 \%$ de la población hacia $1984{ }^{18}$.

\section{DE LA TELEVISIÓN UNIVERSITARIA A LA TV COMERCIAL}

A pesar de que desde los inicios de la televisión en Chile se presentaron tensiones entre las visiones educativa y comercial de este medio de comunicación, el privilegio del que gozaron las universidades en el manejo de los canales aseguró una programación con tendencia hacia lo cultural por largos años. En este sentido, resulta elocuente la declaración emitida por el Consejo de la Universidad de Chile en 1963 en relación con la televisión comercial:

"El instrumento técnico de la televisión [...] puesto al servicio de la educación y la cultura, con ese claro sentido de responsabilidad pública que no pueden imprimirle los intereses privados de lucro, es un instrumento difícilmente reemplazable en la tarea de llegar con ellas hasta las grandes masas, y [...], responder en el plano educacional y cultural a las apremiantes necesidades de su desarrollo"19.

\footnotetext{
17 2008: 392.

18 Rojas y Rojas 2008: 392.

19 Fuenzalida 1983: 15.
} 
En 1970, y tras largos años de debate y presiones por parte del sector privado para empujar un modelo de TV comercial, el funcionamiento de la televisión se reguló mediante el decreto de la Ley 17.377. Uno de los aspectos gravitantes respecto de los que esta versaba, fue el financiamiento de la televisión. En este sentido, se establecieron dos mecanismos para la recaudación de fondos: por una parte, los fondos provenientes de la actividad publicitaria de duración regulada, y por otro, los fondos aportados por el Estado. Este sistema mixto, según directores ejecutivos de estaciones universitarias, "daba una importante cuota de libertad para programar" 20 , es decir, los canales se guiaban por pautas internas y no por criterios comerciales; y su norte seguía siendo lo que se dio en llamar la vocación de "servicio público", que se instalara desde los inicios de la TV universitaria ${ }^{21}$.

La ley de 1970 establecía claramente que la propaganda contratada por los canales de televisión no podría determinar los contenidos de la programación ${ }^{22}$. Sin embargo, tras el golpe militar de 1973, lo que fuera una larga lucha entre las visiones educativa y comercial de la TV, se inclinó a favor de esta última en forma definitiva, y en 1975 se decretó el autofinanciamiento de la TV, sistema que derivó en una incidencia mucho mayor de los auspiciadores en la programación. Se permitió la exhibición de publicidad sin limitaciones, y con ello, la inversión en avisaje creció de forma explosiva. Esta consiguió su punto más alto en 1981, con una inversión de 221 millones de dólares en publicidad, que si los comparamos con los 7,1 millones de dólares invertidos en 1975, nos habla de una TV cada vez más influida por criterios comerciales. Estos cambios a nivel del financiamiento de la televisión tuvieron una repercusión directa en el tipo de programación. Según Durán ${ }^{23}$, a partir de esta transformación se "tendió a privilegiar el entretenimiento liviano en la forma de concursos, shows musicales, películas, teleseries y telenovelas”, programas que abundaron en la pantalla chica desde la fecha en adelante en Chile.

\section{EL IMPACTO DE LAS TRANSFORMACIONES DE LA TV EN LA PROGRAMACIÓN INFANTIL}

La programación infantil, por su parte, también experimentó modificaciones a partir del surgimiento y creciente protagonismo de la televisión comercial. A pesar de ello, el modelo educativo persistió, aunque siendo progresivamente desplazado y presionado a incorporar transformaciones que lo acercaran al nuevo enfoque.

Coincidentemente con el carácter educativo de la televisión universitaria, hasta 1975 los programas para niños tuvieron primordialmente un objetivo formativo. Ejemplo de este modo de hacer TV infantil lo constituye el memorable Pin Pon (1965-1969, Canal 13; 1970-1974, Televisión Nacional). Este programa representa -junto con otros como $E l A B C$ del Tío Jorge, o Cantos y Rondas con Mamita Clara, emitidos durante la década de 1960- la vertiente más fiel a los objetivos propuestos en la época universitaria de la TV, es decir, eran programas hechos principalmente para educar.

No obstante, según Durán ${ }^{24}$, una vez instalada la dictadura militar, "los programas primordialmente educativos tendieron a hacerse menos frecuentes, dando paso a las fórmulas mixtas, que intentaban combinar educación y entretenimiento, o bien, en lo que constituyó una novedad, a programas cuyo propósito declarado era entretener, nada más”. En este

\footnotetext{
20 Fuenzalida 1983: 16.

21 Durán 2012.

22 Hurtado et al. 1988.

23 2012: 115.

24 2012: 117.
} 
estilo "mixto" se emitieron varios programas durante los años setenta y ochenta, como Ya somos amigos (1975-1979), animado por la educadora de párvulos Patricia Undurraga ("Tía Patricia") y con Raúl "Florcita Motuda" Alarcón a cargo de la música; o la Cafetera Voladora, su sucesor de 1979. Otros programas que buscaron conjugar la educación con la entretención, fueron El rincón del Conejito TV, el Show del cumpleaños feliz o Valle Alegría.

A fines de los setenta y principios de los ochenta se empezó a producir una marcada diferencia entre los programas de carácter "mixto" y aquellos destinados expresamente a la entretención. En relación con estos últimos, Durán señala que Los Bochincheros (1976-1983) puede considerarse como el primer programa en:

"dar el salto de la televisión universitaria a la comercial, por su énfasis en la entretención y su consecuente falta de pretensiones pedagógicas, por haber intercalado secciones en vivo y dibujos animados y por haber incorporado concursos con premios de interés para los niños, todas tendencias que se acentuarían en los años posteriores" 25 .

Una vez que Los Bochincheros cesaron de transmitirse, surgieron dos programas infantiles que marcaron la infancia de los ochenta y que constituyen los ejemplos a analizar en el presente trabajo: Masamigos, transmitido entre 1983 y 1984 por Canal 11 y trasladándose en 1985 a Canal 7 con el nombre de Mazapán; y Cachureos, que fue emitido por Canal 7 desde fines de 1983 y que permaneció en pantalla hasta el 2008, tras numerosos cambios de estación.

\section{MOTIVACIONES EN LA GESTACIÓN DE LOS PROGRAMAS MASAMIGOS Y CACHUREOS}

Los programas Masamigos y Cachureos se han tomado como ejemplo en tanto responden a dos modelos distintos de programación infantil que coexistieron en los años ochenta, el educativo y el comercial. Quisiera dejar en claro que en este estudio no pretendo señalar que las características de las músicas utilizadas como ejemplo sean necesariamente similares a otras de programas cuyo enfoque compartan. Esto, debido a la multiplicidad y heterogeneidad de propuestas que hubo en la época que impiden erguir a alguno de ellos como "representativo" de un enfoque particular. No obstante, sí es posible establecer vínculos entre los modelos televisivos y las músicas compuestas para estos programas, como veremos.

Por otra parte, también se han tomado como ejemplo en tanto son programas que, a pesar de los años transcurridos desde sus primeras apariciones en televisión, persisten en la memoria colectiva y su proyección ha trascendido al ámbito de este medio de comunicación, principalmente mediante las presentaciones en vivo que hasta hoy realizan sus animadores ${ }^{26}$. Cachureos además es el programa infantil de más larga permanencia al aire en Chile; en tanto, las canciones de Mazapán no solamente son aún cantadas por los niños, sino que dentro del género "música infantil" serían las preferidas de los niños de hoy, como señala una encuesta realizada por UNICEF ${ }^{27}$.

25 Durán 2012: 121.

26 "Mazapán en vivo en Mall Sport", www.adondevamos.cl (27 de noviembre 2018); "Cachureos en Hualpén”, www.agendaconce.cl (s. f.).

27 Fondo de las Naciones Unidas para la infancia, UNICEF 2012. 
El grupo Mazapán surgió en 1980 de la reunión de siete egresadas ${ }^{28}$ del Instituto de Música de la Universidad Católica. En 1981 grabaron su primer disco, Canciones infantiles y Cuento de Navidad, y ese mismo año fueron convocadas a musicalizar el programa Yo me expreso de TELEDUC y luego El rincón del Conejito TV, en Televisión Nacional. Tras dos años de participación en dicho espacio televisivo (1981-1982), Marta Blanco-directora de Canal 11 por esos años- les propuso tener un programa propio en la señal de la Universidad de Chile. Al respecto, Michelle Salazar cuenta: "ahí nos dio pánico, porque nosotras solamente tocábamos y en ese tiempo tocábamos detrás de los atriles, muy serias, no nos movíamos... de actrices, nada" 29 . A pesar de esto, lograron estructurar el programa Masamigos, que se planteó como una propuesta de corte educativo, pero que sin embargo no buscó entregar mensajes de tipo racional-cognitivo, sino más bien propiciar un aprendizaje de orden estético-emocional ${ }^{30}$. No incluían la presencia de niños dentro del set, como otros programas de la época, y su estructura incorporaba representaciones de personajes clásicos vinculados a la literatura infantil, así como también actividades de expresión corporal, rondas, cuentos, juegos y música. Según Carmen Lavanchy, tanto el grupo como el programa de televisión tenían como principio guía propiciar la relación del binomio niño-arte ${ }^{31}$.

En ese sentido, las integrantes de Mazapán postulan la importancia de dar a conocer a los niños la mayor diversidad posible de géneros musicales, entendiendo la música como un mensaje ${ }^{32}$. En tanto su foco está en el arte y la transmisión de este a los niños, señalan que nunca estuvieron dispuestas a hacer propaganda, ni a fomentar el consumo de productos específicos o la compra de determinadas marcas, pues en palabras de una de sus integrantes, "no nos interesan ese tipo de valores"33. Esto las distinguió de los programas de corte comercial que se emitieron durante la época, y definió en gran medida la estética de su propuesta televisiva.

Un universo muy distinto fue el que configuró Cachureos. El programa surgió en 1981, -en palabras de su creador Marcelo José Raúl Hernández, más conocido como “Marcelo”-, cuando:

un par de sobrinos míos que eran bien despiertos, como gracia, cantaban los comerciales de la televisión, y yo dije, qué buena esta técnica. Con una canción comercial, con un comercial, digamos, los niños aprenden cosas. Y yo dije por qué no hacer lo mismo, ocupando esa técnica y hacerlo con cosas importantes, como por ejemplo, ¿por qué es malo comer tanta azúcar? o ¿por qué flotan los barcos?, etc...y así nació Cachureos $^{34}$.

Heredero del estilo de Los Bochincheros, Cachureos se presentó como el continuador de este tipo de programa de entretención para niños, inspirados en el modelo del exitoso Sábados Gigantes, donde la publicidad estaba plenamente incorporada al programa mediante concursos y secciones auspiciadas por marcas comerciales. Si bien en sus primeros años Cachureos se planteó con una fórmula más bien mixta, con un set ambientado en una especie de patio interior y un grupo de niños que se reunían a conversar con Marcelo acerca de temas diversos y educativos, hacia 1988 el formato cambió radicalmente para transformarse en el programa infantil que perduró por más tiempo en la TV nacional. El

28 Cecilia Álamos, Victoria Carvallo, María de la Luz Corcuera, Carmen Lavanchy, Verónica Prieto, Michelle Salazar y Cecilia Echenique.

29 “Mazapán. Clásico de la música infantil”. 2008.

30 Fuenzalida 1985: 49.

31 Fuenzalida 1985: 44.

32 “Mazapán: Entrevista en Una Belleza Nueva". 2014.

33 Lagaz s.f.

34 "Menú a la carta - La historia de Cachureos". 2014. 
nuevo formato consistió en un set similar al de Los Bochincheros, atiborrado de niños que esperaban ansiosos el momento en que el animador daba el "vamos" con un vociferado “iel grito, el grito, el gritoooooo?”, sello característico del programa. Además, se incorporaron personajes como "El Señor Lápiz”, “Epidemia”, el "Tiburón”, etc.; los juegos adquirieron el formato de concursos donde los niños competían por ganar productos de las marcas auspiciadoras, y las canciones comenzaron a tomar un mayor protagonismo. El aspecto educativo del programa fue quedando cada vez más de lado para dar paso a una suerte de show de variedades para niños.

\section{ANÁLISIS MUSICAL DE MASAMIGOS Y CACHUREOS}

Para al análisis musical, he escogido una canción representativa de cada programa: "La vaquita loca" para Masamigos, y "El profesor distraído" para Cachureos. La primera, forma parte del primer disco del grupo Mazapán, llamado Canciones infantiles y Cuento de Navidad (1981); en tanto la segunda, la encontramos en la producción Cachureos 88 (1988). Ambas son aún tocadas en vivo, como consta en los registros de sus presentaciones en el festival de música Lollapalooza en 2017 y 2016, respectivamente ${ }^{35}$, por lo que he considerado que son canciones que revisten una cierta importancia por sobre el resto de su repertorio, al menos en términos de recepción.

Como metodología para el análisis utilizaré fundamentalmente las propuestas de Rubén López Cano ${ }^{36}$ acerca de intertextualidad en música. Según este autor, mediante la intertextualidad,

“... el lector establece relaciones estilísticas, genéricas o autorales entre aquello que lee y aquello que no tiene ante sus ojos, pero que atesora en sus competencias. En música ocurre algo similar: el oyente establece relaciones de parentesco entre momentos de varias obras estableciendo redes que colaboran en sus procesos de comprensión".

Considerando lo anterior, es importante mencionar que mi análisis se basa en las relaciones que a partir de la audición de la música de estos programas pude establecer -es decir, se sostiene en mis propias competencias como auditora-, y que estos vínculos, así determinados, luego busco ponerlos en relación con los objetivos que los propios creadores han sostenido acerca de su música y el carácter de sus programas de TV.

López Cano define cinco tipos de relación intertextual en música: cita, parodia, tópico, transformación de un original y alusión ${ }^{37}$. Es a partir de las dos últimas que revisaré estas canciones, facilitando las definiciones específicas cuando sea pertinente más adelante en esta sección.

\section{ANÁLISIS DE “LA VAQUITA LOCA” DE MAZAPÁN}

Para el análisis de esta canción, compuesta por Carmen Lavanchy, me centraré esencialmente en su estilo compositivo, el que abordaré desde la alusión como categoría intertextual. Esta corresponde a,

35 Revisar la bibliografía para grabaciones de estas presentaciones en la plataforma electrónica Youtube.

36 2007: 31.

372007. 
"referencias vagas, posibles o latentes a estructuras, sistemas o procedimientos generales que una obra hace hacia el estilo general de un autor, tipo de música, o incluso una cultura musical. No son evidentes y requerimos que el autor o un especialista nos señale su existencia" 38 .

Considero que en esta canción se hacen presentes al menos dos alusiones: a las composiciones y metodología de enseñanza musical para niños del compositor alemán Carl Orff (1895-1982), así como a procedimientos de composición característicos del Renacimiento y el Barroco.

El estilo e instrumentación de esta canción, similar al de muchas canciones del grupo, están inspirados en las propuestas de la Orff-Schulwerk, una metodología de educación musical creada por el compositor Carl Orff en la década de 1930. El proyecto educativo de Orff propugnaba la idea de una "música elemental", inspirado en la teoría de la recapitulación postulada por G. Stanley Hall hacia 1895. Esta última promovía la idea de que los niños volverían a representar la historia de la civilización occidental al tiempo que pasan por distintas "etapas" de desarrollo ${ }^{39}$. A partir de esta concepción, Orff sostiene que "la música para niños que aspire a actuar profundamente en su espíritu debe ser música elemental, diríamos primitiva" 40 , y que el desarrollo musical del niño "corresponde al mismo que se dio históricamente desde el pentatónico al diatónico” 41 . Es por esta razón que Orff propone que la educación musical comience con el uso de la escala pentatónica y los modos musicales antiguos, así como la armonía simple de notas pedales y los ostinatos a nivel rítmico ${ }^{42}$. Todos estos son elementos que encontramos en la música de Mazapán, y particularmente en "La vaquita loca".

Esta canción está construida sobre una escala pentáfona con "tónica” en sol (sol-lasi- re-mi), que sirve de material de base para los ostinatos rítmico-melódicos en los que se construye una textura polifónica de carácter contrapuntístico que acompaña a la melodía principal con sus diversas variaciones. La instrumentación consta de cascabeles, xilófonos, voces femeninas, cajita china y flauta dulce tenor. Todos estos son parte del instrumental Orff, que comprende el uso de la voz así como también de instrumentos de percusión de altura indeterminada (como las cajitas chinas y cascabeles), instrumentos de percusión de altura determinada (que en esta canción no se utilizan), instrumentos armónicos, entre los que encontramos los xilófonos como parte de los instrumentos de placa, y la flauta dulce, la que constituye la excepción al uso de instrumentos de viento o cuerda dentro de esta metodología ${ }^{43}$. Vemos así, que "La vaquita loca" utiliza un conjunto instrumental característico de la pedagogía Orff.

El siguiente cuadro presenta un esquema de la canción que nos permite apreciar las texturas, entradas e interacción de la instrumentación dentro de la misma (ver Ejemplo 1). La canción está estructurada -en términos del uso de la instrumentación- de forma muy didáctica. Esto, pues si bien la melodía principal (mp) está siempre acompañada por el ostinato del xilófono y la cajita china, cada vez que se reexpone es acompañada por distintas melodías contrapuntísticas. Así, la primera vez, la melodía principal a cargo de una voz femenina está acompañada por otras tres voces femeninas; la segunda vez, es la

38 López Cano 2007: 36.

39 Schwartzman 1978, citado en Minks 2002, donde se expone una revisión crítica de esta teoría.

40 Graetzer y Yepes 1961: 9.

41 Sanuy y González 1963: 12.

42 Sanuy y González 1963: pp?

43 Graetzer y Yepes 1961: 46. Para mayor detalle acerca de la instrumentación Orff, véase Sanuy y Sarmiento 1963. 
flauta la encargada de hacer el contrapunto a la voz femenina principal, para luego, en la tercera reexposición, ceder tanto la melodía principal como su contrapunto a dos xilófonos. Finalmente, en la última repetición, todos los elementos antes expuestos por separado, se unen en una textura compleja y densa, donde conviven todas las líneas melódicas y los ostinatos rítmicos antes mencionados.

Entiendo esta decisión estilística en el modo de presentar los instrumentos, por una parte, desde un afán pedagógico, ya que de esta forma se permite que el niño aprehenda progresivamente las distintas sonoridades que construyen la canción. Esto porque los elementos se agregan de forma gradual, para finalmente construir una textura compleja que muestra lo que puede surgir de la reunión de varios componentes sencillos. Y por otra parte, también lo entiendo desde una perspectiva de búsqueda artística, ya que se dota a una melodía simple y repetitiva de un acompañamiento móvil, variado e interesante, construyendo de este modo una propuesta musical más compleja y rica en capas auditivas.

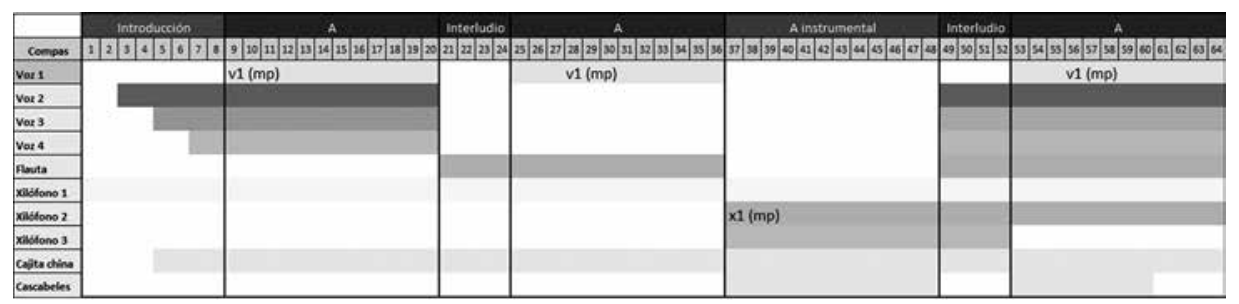

Ejemplo 1. Instrumentación, entradas y texturas.

En cuanto al uso de la escala pentáfona y a los ostinatos rítmicos que se han mencionado como característicos de la música infantil de Orff, los siguientes ejemplos musicales muestran las similitudes en relación con estos aspectos entre "La vaquita loca" y un ejemplo extraído de la grabación Orff-Schulwerk: Música Poética (1995-1996), compilación de composiciones para niños de Carl Orff y basadas en su metodología pedagógica:

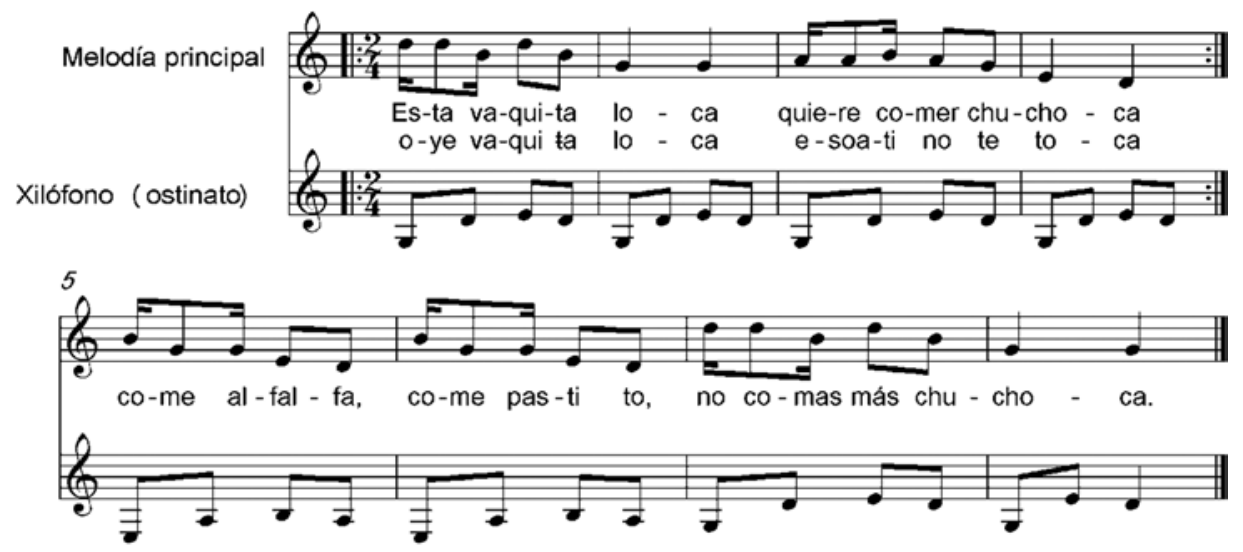

Ejemplo 2. Mazapán. "La vaquita loca" (1981). Compases 9 al 20.

Melodía principal y ostinato xilófono. Transcripción propia. 

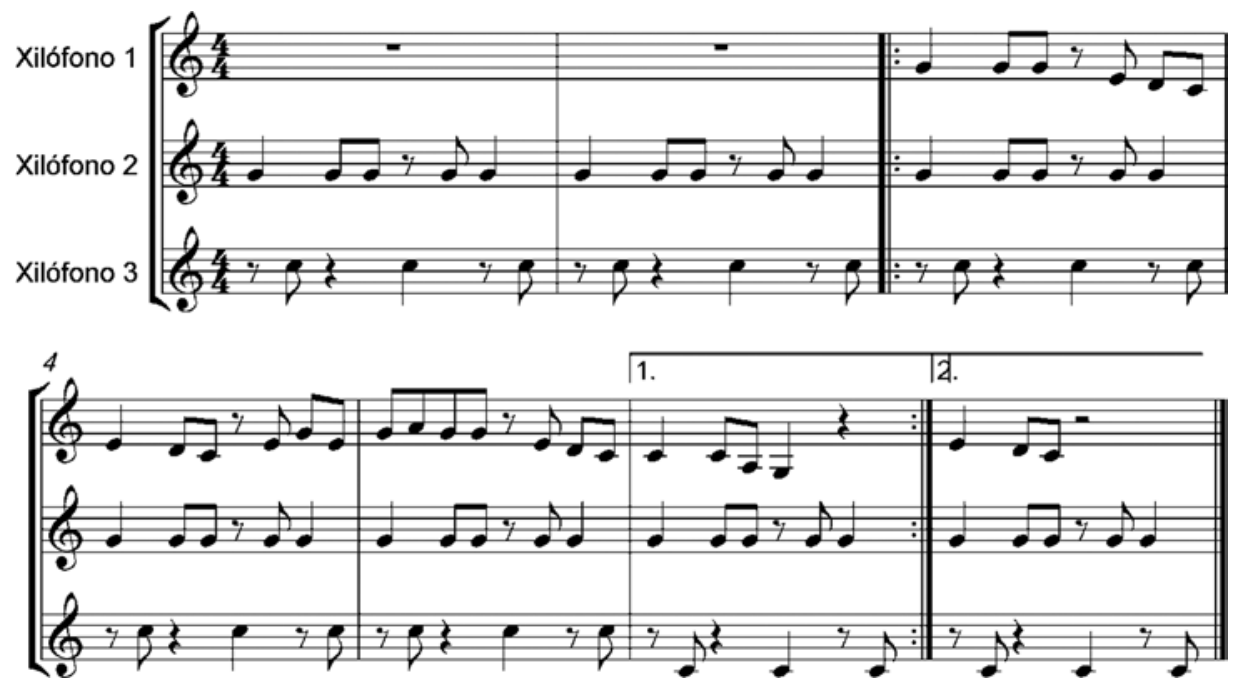

Ejemplo 3. Carl Orff. "Vier Stücke Für Xylophon. Allegretto, für Sopran-, Altxylophon, Maracas, Schellentrommel und Tom-Toms" (1995). Compás 1 al 12. Transcripción propia.

En términos de la melodía principal, "La vaquita loca" comienza con una nota repetida que luego baja una tercera menor descendente, al igual que la obra de Orff, donde el procedimiento es similar. Esta coincidencia no es casual, ya que dentro de la metodología del compositor, este es el intervalo considerado como el más sencillo y, por tanto, es el que se utiliza para comenzar el trabajo melódico dentro de este sistema pedagógico. Luego aparecen gradualmente el resto de los intervalos que conforman la escala pentatónica ${ }^{44}$. Por otra parte, ambas melodías comienzan en la quinta nota de la escala para culminar en la tónica, y el ámbito que abarcan es de una octava para la canción de Mazapán y una novena para la pieza de Orff.

En cuanto a los ostinatos rítmicos, su presencia es determinante en ambas composiciones, como podemos ver en los compases que sirven de ejemplo. Para los dos casos, este recurso transita a lo largo de toda la pieza, otorgándole parte importante de su sonoridad característica. Al respecto, Sanuy y González señalan que "el obstinato es, quizá, la figura musical más apreciada por los niños, la más útil para la instrumentación por su gran efecto armónico y la más formativa, dada su repetición obstinada" ${ }^{45}$; lo que nos revela la intención didáctica en el uso de este recurso.

El caso de "La vaquita loca" no se revela como un ejemplar aislado en el uso de los recursos provenientes de la metodología Orff por parte de la agrupación Mazapán. Encontramos el uso del instrumental propio de este método en canciones tan reconocidas como "La chinita Margarita", "Navegando" o "El Globito", lo que muestra que se trata de una propuesta estilística coherente del grupo más que un hecho azaroso dentro de su discografía.

Como se dijera anteriormente, me propongo también señalar la presencia de una segunda alusión intertextual, referida a la utilización de procedimientos composicionales característicos del Renacimiento y el Barroco dentro de la música de Mazapán. Hablo

44 Graetzer y Yepes 1961: 8.

45 Sanuy y González 1963: 81. 
específicamente del uso del contrapunto como técnica principal de construcción textural de la canción. Recordemos que este término "apareció en el siglo XIV (contra y punto, en el sentido de nota) y que designa el arte de superponer varias líneas melódicas" 46 . Se desarrolló fundamentalmente durante el Renacimiento y el período Barroco, y aunque persiste hasta hoy (ya que se trata de un procedimiento y no de un rasgo exclusivo de un género o estilo), es característico de la música occidental compuesta en dichos períodos. En el siguiente ejemplo (ver Ejemplo 4), podemos ver un extracto de los compases finales de "La vaquita loca", donde todos los instrumentos participan colaborando con una línea melódica independiente, que se teje en contrapunto con el resto:

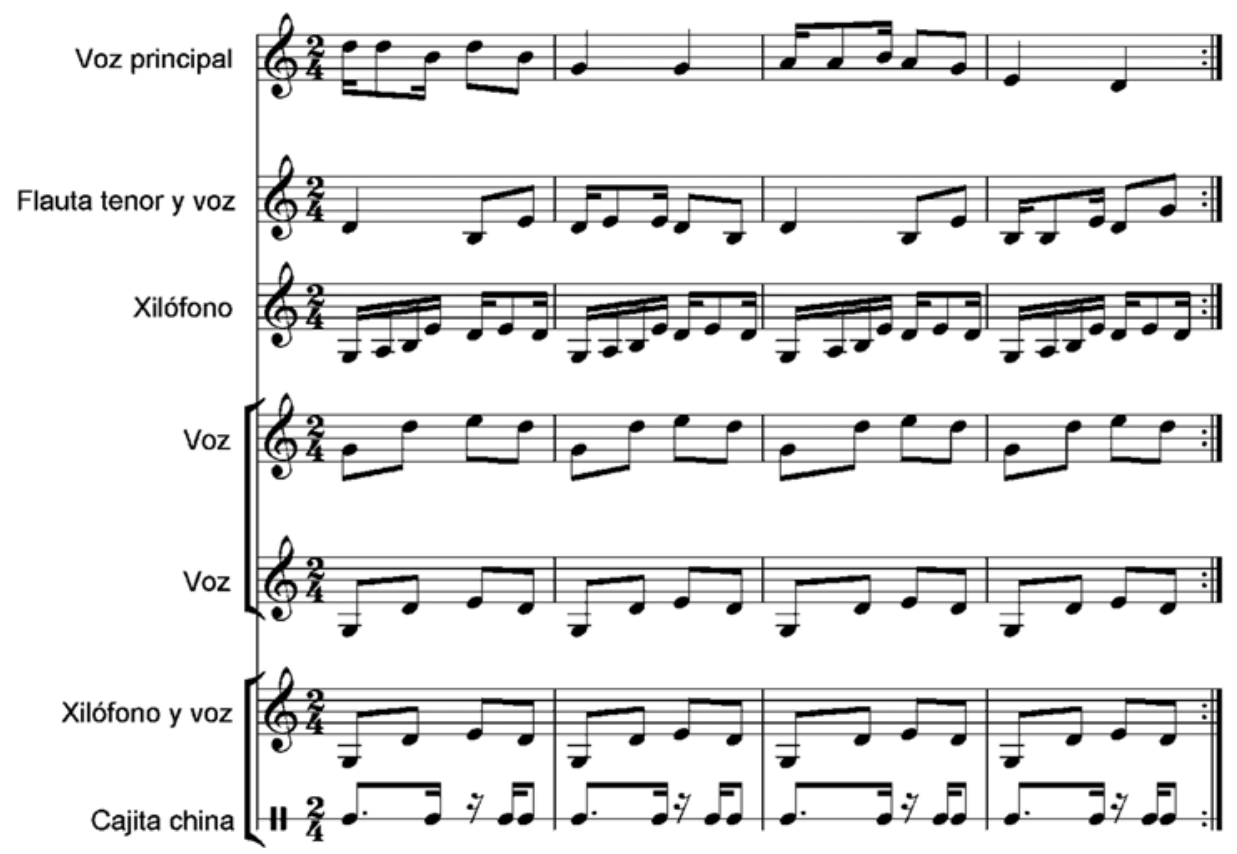

Ejemplo 4. Mazapán."La vaquita loca”(1981). Compases 53 al 60.

Trama polifónica completa. Transcripción propia.

No sorprende, sin embargo, la presencia de esta alusión si consideramos la historia del grupo Mazapán. Antes de conformarse como tal, la mayoría de sus integrantes formaban parte de una agrupación dedicada precisamente a la Música Antigua, cuyo nombre era Fontegara y que, entre otras cosas, daba conciertos educativos en colegios ${ }^{47}$. Este interés por la incorporación de elementos vinculados a la corriente de la Música Antigua, no solo se observa en el ejemplo que acabo de referir, sino también en varias de las composiciones de grupo, como "Fuga de la cartera", "Taco y punta", "Sauce llorón”, "Arturo el dragón" o "Caracol Agustín”, entre tantas otras composiciones en las que, ya sea por los instrumentos

46 Darbon 2011: s.n.

47 “Mazapán: Entrevista en Una Belleza Nueva”. 2014. 
escogidos, o bien por los procedimientos utilizados, queda expuesta la opción estilística del grupo.

Tanto las alusiones al método Orff como a la música renacentista y barroca, hacen referencia a un universo musical construido desde la educación y el arte, con énfasis en estilos considerados "cultos". La propuesta televisiva de Masamigos se revela así en sintonía con estos referentes.

\section{ANÁLISIS DE “EL PROFESOR DISTRAIIDO” DE CACHUREOS}

Esta canción del programa Cachureos fue incluida en su segunda producción discográfica, Cachureos 88 (1988). Si bien más tarde, en 2001, se volvió a editar con un nuevo arreglo, es a esta primera edición a la que me referiré en el presente trabajo. "El profesor distraído" fue compuesta por los argentinos Carlos Balá, Dante Gilardoni y Filinto Rebechi en 1977, y formó parte del disco ¿̇Y qué gusto tiene la sal?, del primero de ellos. Balá es un comediante argentino que por largos años se ha dedicado a la entretención infantil, siendo su programa más recordado El show de Carlitos Balá (1979-1982; 1987). Tomando en cuenta que la canción interpretada por Marcelo de Cachureos sería una versión, o cover de Balá, la analizaré considerándola una transformación de un original, categoría intertextual propuesta por López Cano, la que me servirá como punto de partida. Al respecto, este autor señala que:

"Por diversas razones una obra puede ser revisada, arreglada, versionada o incluso, reescrita por su autor u otro compositor. [...] En este caso se producen casos interesantes en relación con la identidad de una obra: ¿cuántas transformaciones puede resistir una obra para seguir siendo considerada la misma y no otra? ¿Todas la versiones, arreglos, orquestaciones o reducciones de una obra musical son ocurrencias, partes o variantes de la misma obra o deben considerarse obras distintas?" 48 .

A pesar de la utilidad de esta reflexión desde una perspectiva filosófica acerca del cover, para una aproximación más operativa, utilizaré las cuatro categorías hermenéuticas que propone Martín Azar ${ }^{49}$. Este autor considera cuatro niveles de análisis del cover ordenados jerárquicamente, donde en un primer estrato se encuentran elementos formales fundamentales como el ritmo, la armonía y la melodía. En un segundo nivel estarían los arreglos, en el tercero, la instrumentación, y finalmente, en un último nivel, estaría la interpretación o performance, donde las diferencias tienden a hacerse aún más sutiles que en todo el resto de los estratos. Tomando en cuenta estas jerarquías, es posible establecer qué tan lejos se encuentra una versión de otra en el ámbito del cover musical, lo que permitirá situarla dentro de una red de significados y establecer el grado de conexión entre ambas. Veamos entonces cómo se articulan estas categorías en la versión que hace Cachureos (1988) y aquella de Balá (1977).

Tanto el ritmo como la melodía y la armonía de la canción se mantienen prácticamente intactos. La única excepción la constituye el final que aporta Marcelo, que no se encuentra en la versión original, ya que esta termina con un recurso de fade out. Ambas versiones están en la tonalidad de do mayor, y transitan armónicamente como sigue (ver Ejemplo 5):

48 López Cano 2007: 33.

492011. 


\section{Estrofa 1}

I

El profesor distraído

Siempre está muy apurado

V

O se olvida de la ropa

o en los lentes se ha sentado

\section{Estrofa 2}

I

Él es hombre muy sincero

ii

Y trabaja todo el año

Sirve mate en el sombrero

o se olvida algún zapato

\section{Coro 1}

IV

Pero lo queremos

Porque es muy buenito $\mathrm{V} / \mathrm{V}$

Pone buenas notas

$\mathrm{Y}$ tiene buen corazón

\section{Coro 2}

IV

El otro día dijo

I

La Santa María,

$$
\mathrm{V} / \mathrm{V}
$$

La Niña y la Pinta

Pasan por Constitución

\section{Coda}

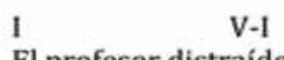

El profesor distraído

Ejemplo 5: Cachureos. "El profesor distraído" (1988). Letra y grados armónicos. 
Ahora bien, el segundo y tercer nivel de análisis (arreglo e instrumentación) en este ejemplo se encuentran íntimamente imbricados. La versión original de "El profesor..." consta de la siguiente instrumentación: voz principal masculina, coros femeninos, guitarra eléctrica, bajo, batería, piano y bronces. Esta formación instrumental corresponde a la formación clásica del rock and roll, la que según Scaruffi ${ }^{50}$, permite enfatizar la importancia de la línea melódica por sobre los arreglos instrumentales, siendo este un rasgo típico de la música pop. Esta instrumentación es también la más usada para acompañar a los intérpretes de la Nueva Ola argentina. Ejemplos de esto son los grandes éxitos "La felicidad" o "Bienvenido amor" de Palito Ortega, uno de los exponentes de mayor repercusión de este movimiento en dicho país.

Dentro de esta canción son los bronces los encargados de configurar los elementos principales del arreglo, y los encontramos tanto en la introducción instrumental como en el coro y la última de las estrofas. Otro elemento que destaca es el uso de coros femeninos, que funcionan como eco en las estrofas y se suman a la voz principal en el coro. Este es un recurso muy usado también por los intérpretes de la Nueva Ola en general. Las canciones que he mencionado de Palito Ortega son un buen ejemplo en este sentido. De este modo, considero que la versión original de "El profesor distraído" -debido a su instrumentación, el uso de coros femeninos y la época en la que fue compuesta-se nutre del estilo de la Nueva Ola argentina para configurar una canción infantil mediante una letra de carácter cómico.

La versión de Cachureos, en tanto, presenta una instrumentación que consta de voz masculina principal, coros femeninos, baterías programadas, y sintetizadores. A pesar de eliminar la instrumentación acústica, la versión de Cachureos se mantiene cercana a la de Balá. En este sentido, podría pensarse que la versión de Cachureos no busca realmente transformar el original, porque el arreglo es el mismo, pero en versión sintetizada. Sin embargo, creo que en este caso el arreglo funciona como una alusión al universo synth-pop que fuera muy popular en la década y que se incorpora más bien como una forma de "modernizar" la versión original para acercarla a la música de moda de ese momento.

Si bien el uso de sintetizadores y sonidos electrónicos en la música pop comenzó con las experimentaciones de Brian Eno y Kraftwerk hacia fines de los setenta, la gran avalancha de pop sintetizado, o synth-pop, llegó a partir de 1981. De acuerdo con Scaruffi ${ }^{51}$, el dúo se transformó en la formación preferida por aquella época, ya que permitía reemplazar a una orquesta completa y su sección rítmica con solo un teclado (primer integrante), al tiempo que se mantenía la figura del antiguo crooner (segundo integrante). De esta manera se hacía la misma música pop de antaño, pero con instrumentos modernos, con el beneficio además de ser un formato mucho más económico y, por tanto, rentable. La tendencia de incluir sonidos sintetizados en el pop más mainstream persistió durante toda la década de los ochenta, y fue una de las vertientes musicales de mayor llegada al público masivo, como bien ilustran las listas que ofrece la revista Billboard ${ }^{52}$.

En Chile, en tanto, fue el grupo Aparato Raro el que dio inicio a esta tendencia hacia 1984. Gracias a sus autocensuradas letras contrarias al régimen militar de la época, lograron tener una alta rotación en las radios y ser invitados frecuentes de programas televisivos masivos como Sábados Gigantes ${ }^{53}$, haciendo de su sonoridad un referente de moda por aquellos años. En otra línea, la popularidad del uso de sintetizadores en esa época

\footnotetext{
50 2005: s. n.

51 2005: s. n.

52 Top 100 songs of 1988 s. f.

53 Ponce 2013.
} 
se vio reflejada también en el hecho de que este sonido se convirtió en el estándar de la producción de baladas durante la década de los ochenta, como señala Party ${ }^{54}$, quien cita el ejemplo de la canción “Ay, amor" (1989) interpretada por Myriam Hernández, canción en la que se observa el uso de instrumentación completamente sintetizada que recoge la tónica estilística de la época.

Por otra parte, la línea original de los bronces en la versión de Cachureos se simplifica al pasar al formato sintetizado. Esto, pues omite la línea melódica más grave realizada por los bronces en la versión original, quedándose solamente con la más aguda. La batería, por su parte, pierde las posibilidades tímbricas que le otorga el uso del hi-hat y la caja, en la unificación de la base rítmica en el timbre único de la batería programada. El piano, en tanto, sería la excepción a esta pérdida tímbrica, pues es reemplazado por al menos tres diferentes timbres sintetizados, que realizan acompañamientos en las estrofas, pero no así en el coro. La guitarra de la versión de Balá, por su parte, es omitida en la de Cachureos. Finalmente, los elementos de la instrumentación que se mantienen intactos son el bajo y los coros femeninos, los que preservan su función original.

Es interesante destacar también que el uso de las voces femeninas dentro de la canción tiene relación con el pasado musical de Marcelo. Estos coros son utilizados al estilo de las canciones que le hicieran famoso hacia fines de los sesenta. Basta mencionar su primer gran éxito como cantante solista, "Mundo feliz" (1969), donde el acompañamiento de voces se presenta de modo muy similar a aquel utilizado en "El Profesor...", en una especie de autocita. Este recurso lo llevó al extremo al grabar dicho éxito en un disco de Cachureos en 1993, en versión renovada, mediante el uso de sintetizadores una vez más.

Por último, en el cuarto nivel señalado por Azar -la interpretación o performance- se encuentra el uso de la voz que hace Marcelo, que se caracteriza por predominar en la mezcla por sobre las voces acompañantes y la instrumentación. Este protagonismo vocal es propio de géneros musicales como la balada ${ }^{55}$, donde la figura del cantante destaca por sobre el acompañamiento musical, y busca hacerse reconocible por el público, en la línea de los llamados "ídolos musicales". En la canción analizada, Marcelo utiliza algunos recursos vocales para darle un cariz cómico a su interpretación (consonantes marcadas, cambios leves en la voz a modo de personaje, pequeñas risas, entre otras), y cambia el timbre profundo y varonil que utilizara en algunas de sus interpretaciones como baladista en los años setenta, por un timbre menos denso, más liviano y algo más nasal; probablemente para hacer una distinción entre la voz con la que apelaba a sus fans femeninas, y esta nueva voz más "amistosa", que busca asegurar su llegada al público infantil. No obstante, en muchas de sus canciones posteriores y en varias de la misma producción discográfica a la que pertenece esta canción, Marcelo retoma el estilo que lo identificara como cantante solista.

Considero que es por medio de los dos últimos niveles de análisis que hemos revisado que es posible afirmar que la versión de Cachureos de "El profesor..." no pretende ser una "copia" de la de Carlos Balá, ya que su interpretación es más cercana a lo que fuera Marcelo como baladista, que al estilo del comediante argentino. Por otra parte, el uso de sintetizadores se transformará en los años sucesivos en parte de la identidad sonora de Cachureos, en la que los arreglos para las canciones propias y las versiones de canciones de moda, estarán marcadas por esta sonoridad sintetizada.

Vemos de este modo que el universo desde el que se nutre Cachureos, para configurar su propuesta musical, es el de géneros y canciones de la música popular de gusto masivo. Esto queda aún más en evidencia al revisar los títulos que han mantenido a Cachureos al tope

\footnotetext{
54 2008: 73.

55 Gónzalez y Rolle 2004: 544-463.
} 
de la popularidad por largos años. Canciones como "Tarjetita de invitación" de Adrián y los Dados Negros, "El baile del perrito", original de Wilfrido Vargas o "Ritmo Cachureos", versión de "Ritmo de la noche" del grupo The Sacados, son ejemplos de la inclinación de los creadores de este programa a incluir música de carácter comercial y éxitos probados en el mundo adulto, en un programa destinado a los niños.

La canción que he analizado toma como base una canción para niños exitosa en Argentina, que a su vez remite al estilo de la Nueva Ola, movimiento musical de gran popularidad tanto en Argentina como en Chile, y del que el propio Marcelo alcanzó a participar en sus comienzos como baladista. Por otra parte, mediante los cambios en la instrumentación, la canción alude a otro género que hacia 1988 estaba en boga -el synt-pop-, configurando así, por medio de una yuxtaposición de géneros populares, una propuesta de llegada masiva para público infantil.

\section{CONCLUSIONES}

En la presente comunicación he revisado el proceso de cambio por el que atravesó la televisión chilena hacia mediados de la década de los setenta, esto es, el paso desde un sistema mixto de financiamiento, con aportes tanto publicitarios como del Estado, a uno autofinanciado, sustentado exclusivamente por la publicidad. Fue desde aquí que se gestó una nueva forma de abordar la producción televisiva en Chile, que propició el surgimiento de un modelo comercial de TV. Este dio un mayor énfasis al entretenimiento en detrimento de la cultura y la educación ${ }^{56}$, lo que se hizo extensivo a la programación infantil, con la consiguiente emergencia de diversos programas que adscribieron a este modelo. Aún así y aunque en menor medida, el modelo educativo persistió, generándose de este modo una coexistencia de modelos televisivos con clara preeminencia del de carácter comercial durante los años ochenta en Chile.

A partir de esta constatación, el objetivo principal de este trabajo fue revisar si efectivamente los cambios en la estructura y objetivos generales de la televisión chilena -que derivaron en la coexistencia de dos modelos televisivos divergentes- tuvieron una incidencia en la música que se compuso para los programas infantiles, como sostuve en mi hipótesis. Para ese efecto se analizaron las músicas de los programas Masamigos y Cachureos, así como las motivaciones desde donde surgieron, considerando que el primero de ellos adscribía a un estilo de televisión cercano a los objetivos educativos de lo que fuera la televisión universitaria; en tanto, el segundo, estuvo asociado a lo que entendemos por televisión comercial y cuyo auge fue propiciado por la ley de autofinanciamiento.

Con el análisis de canciones representativas de los programas estudiados vimos que Masamigos sostuvo su universo sonoro principalmente en metodologías pedagógicas y música vinculada al ámbito académico -o bien, géneros populares, pero tratados a partir de procedimientos propios de la academia-, ofreciendo así una propuesta que buscó educar musicalmente, al tiempo de generar creaciones artísticas para niños. Y que Cachureos, en tanto, se nutrió de géneros musicales de gusto masivo y éxito probado, así como de canciones populares en el mundo adulto, dando forma a una propuesta centrada en la entretención que tuvo una amplia llegada en el público infantil.

Si la televisión universitaria se planteó como un espacio de "servicio público", donde el énfasis estaba puesto en educar, la música de Masamigos se muestra en sintonía con este objetivo, plegándose a un modelo que venía ya en declive desde fines de los setenta

56 Fuenzalida 1983: 20. 
y que en años sucesivos se haría cada vez más escaso. Un síntoma de ello es la temprana desaparición de este programa, debido principalmente a que sus integrantes se negaron a incluir publicidad dentro del mismo ${ }^{57}$. Así, musicalmente hablando, Masamigos no se vio influido por los crecientes criterios comerciales impuestos desde la televisión y se mantuvo más cercano a los ideales de la televisión universitaria, lo que definió en gran parte su estética musical.

Por su parte, la televisión comercial dio mayor importancia a la entretención y el espectáculo, de modo que Cachureos y su estilo musical vinculado a géneros de gusto masivo, se muestra congruente con esta perspectiva. Así, es posible aseverar que los cambios en el modo de hacer televisión sí afectaron la manera en que este programa abordó la creación musical, acercándose no solo desde lo visual a los objetivos de este modelo, sino que también desde lo musical.

En concordancia con lo expuesto, la aseveración de Ana María Ochoa ${ }^{58}$ que he referido al inicio de este trabajo, acerca de que los cambios a nivel de los modos de comunicación de una forma artística implican transformaciones a nivel estilístico, toma cuerpo mediante el análisis realizado. Esto, pues los referentes desde donde se construyen las propuestas musicales de Cachureos y Masamigos se presentan disímiles entre sí, al tiempo que cada propuesta se revela consonante con el modelo de televisión al que adscribe.

Esto habla de que efectivamente es posible pensar en que los cambios estructurales de la televisión y sus nuevos objetivos influyeron a nivel estilístico en la música de los programas que hicieron suyo este nuevo modelo, como sucedió en el caso de Cachureos. En cambio, vemos que Masamigos, si bien no vio alterada su propuesta musical, sí vio afectada su permanencia en pantalla por el hecho de negarse a cambiar su estilo por uno más cercano a lo comercial, denotando que los cambios en la televisión hacían inviable un programa de sus características.

A pesar de lo anterior, resulta claro también que debido a la heterogeneidad de la televisión infantil durante la época -y que ha sido posible develar en este estudio-, estos ejemplos son insuficientes para dar por establecida una relación unívoca entre los modelos televisivos y el tipo de música utilizada en los programas. De este modo, considero que resultaría conveniente ampliar el presente trabajo mediante la incorporación de más ejemplos, para así completar el panorama musical infantil televisado durante la década de los ochenta y profundizar en la relación entre modelos televisivos y música para niños, a la que me he aproximado en el presente trabajo. Si verdaderamente queremos entender esta relación, se hace necesario explorar la totalidad, o bien, gran parte del material disponible.

Es posible remitir de igual modo que, a pesar de las diferencias observadas y su carácter heterogéneo, los programas para niños en su mayoría se plantean desde un discurso que apela a "lo educativo", lo que no necesariamente se traduce a nivel musical, como se ha visto. Esta importancia dada a lo educativo como valor central en el trabajo hecho para niños no sorprende, en tanto la concepción de infancia clásica, y que recién vino a cuestionarse con más fuerza a partir de la década de los noventa, considera al niño como una "tabla rasa" que debe reproducir conocimiento, identidad y cultura a partir de la educación ${ }^{59}$. Esta visión ha sido notoriamente criticada en las últimas décadas, dando como resultado una conceptualización de la infancia que entiende al niño como co-constructor de conocimiento, identidad y cultura. Sin embargo, se puntualiza que:

\footnotetext{
57 “Mazapán. Clásico de la música infantil”. 2008.

58 2003: 22.

59 Ramírez 2007: 29.
} 
"La infancia, como construcción social que es, se halla siempre contextualizada con respecto a un tiempo, un lugar y una cultura, y varía según la clase, el género y otras condiciones socioeconómicas. No existe, pues, una infancia natural o universal, como tampoco existe un niño natural o universal, sino múltiples infancias y niños" ${ }^{\circ}$.

En vista de esto, el concepto "música infantil" resulta -de nuevo- problemáticamente homogéneo, en tanto pasa por alto todo tipo de diferencias de clase, género, o etnia entre los niños. Pues finalmente, ¿qué es "lo infantil" de la música infantil? Bien cabría preguntarse en este sentido, ¿a qué niños están dirigidas estas músicas? ¿Hay una consciencia de parte de los creadores de música infantil de incluir las diversas realidades de la infancia en Chile al momento de crear? ¿Cómo han de ser estas realidades incorporadas en la música de modo de permitir interpelaciones exitosas?

Estas y otras preguntas, así como la heterogeneidad de la música infantil a la que me he referido constantemente a lo largo de este trabajo, son una muestra de la riqueza de este ámbito de estudio. La presente comunicación ha sido solamente una primera aproximación a un tema vasto y con múltiples interrogantes que persisten irresueltas. A pesar de esto último, este trabajo ha aportado con algunas respuestas que nos permiten seguir profundizando en esta línea, así como con preguntas relevantes que nos invitan a ver en este un campo fértil de trabajo a futuro.

\section{BIBLIOGRAFÍA}

Adachi, Mayumi y Sandra Trehub

2000 "Decoding the Expressive Intentions in Children's Songs", Music Perception: An Interdisciplinary Journal, 18/2, pp. 213-224. Disponible enwww.jstor.org/stable/40285909 [acceso: 12 de diciembre 2018].

A DÓNDE VAMOS

2018 "Mazapán en vivo en Mall Sport", Adondevamos.cl, 27 de Noviembre. https://adondevamos. cl/mazapan-en-vivo-en-mall-sport/

Agenda Conce

2018 "Cachureos en Hualpén", Agendaconce.cl, 27 de Noviembre, s. f. http://www.agendaconce. cl/2018/3827/cachureos-en-hualpen-sector-cuatro-canchas

Álvarez Chuart, Jorge

2001 "Primera infancia: un concepto de la modernidad", El Observador, 7, pp. 62-75. www.sename. cl/wsename/OBS7/Observador-7- marzo2011-articulo-jorge-alvarez-chuart.pdf [acceso: 12 de agosto 2014].

Azar, MarTín

2001 "Una que sepamos todos", Revista Luthor 1/3.Disponible en http://revistaluthor.com.ar/ spip.php?article14 [acceso: 12 de diciembre 2018].

Benavides, Carmen Gloria

2014 "Primer encuentro de música infantil Panguipulli 2014", Sonido Nacional (1 de octubre). http://sonidonacional.cl/noticias/primer- encuentro-de-musica-infantil-panguipulli-2014/ [acceso: 3 de septiembre 2014 ].

60 Dalhberg, Moss y Pence 1999, citado en Ramírez 2007: 11. 


\section{BICKFORD, TYLER}

2011 "Children's music", Grove Music Online. Oxford Music Online. Oxford University Press. Disponible en www.oxfordmusiconline.com/subscriber/article/grove/music/A22279 78 [acceso: 12 de diciembre 2018].

2012 “The new 'tween' music industry: The Disney Channel, Kidz Bop and an emerging childhood counterpublic", Popular Music, 31(3), pp. 417-436. DOI: 10.1017/S0261143012000335

BillboARd

1988. Top 100 Songs of 1988-Billboard Year End Charts.Bobborst. www.bobborst.com/popculture/ top-100-songs-of-the- year/?year=1988 [acceso: 27 de agosto 2014].

Chacón, Rodrigo

2014 "Música infantil, tropical y el humor aseguran presencia [en] el Festival de Olmué 2015". La Nación, 16 de octubre. www.lanacion.cl/noticias/cultura-y-entretencion/musica/ musica- infantil-tropical-y-el-humor-aseguran-presencia-el-festival-de-olmue- 2015/2014-1016/085754.html [acceso: 3 de septiembre 2014].

DARbon, Nicolas

2011 "La historia de la música. ¿Una pirámide de la complejidad?”, Gazeta de Antropología, 27/1, artículo 11. Disponible en http://hdl.handle.net/10481/15324 [acceso: 12 de diciembre 2018].

Diario UCHILE

2013 "Disco de música infantil reúne a integrantes de Banda Conmoción y La Gallera", Diario UChile, 13 de agosto. http:/ / radio.uchile.cl/2013/08/13/disco-de-musica-infantil-reune-aintegrantes-de-banda-conmocion-y-la- gallera [acceso: 3 de septiembre 2014].

Díaz, María Eugenia y María Pilar Piracés

1983 "Selección de rondas, canciones y juegos infantiles tradicionales de Chile". Tesis para optar al Título de Profesor de Estado en Educación Musical, Academia Superior de Ciencias Pedagógicas.

Donaire, Claudio y Myriam Paredes Soto

1989 Educación musical: música para el profesor. Santiago: Centro de perfeccionamiento, Experimentación e Investigaciones Pedagógicas.

Durán, SERGio

2012 Ríe cuando todos estén tristes. El entretenimiento televisivo bajo la dictadura de Pinochet. Santiago: LOM.

EL DeBate

2008 "Mazapán. Clásico de la música infantil”, El Debate, agosto. www.programaeldebate.cl/index. php/52-entrevista-a-mazapan-no- estamos-en- tv-porque-nos-negamos-a-vender-publicidad [acceso: 15 de septiembre 2014].

FuenZALida, VALERIO

1983 Transformaciones en la estructura de la TV chilena. Santiago: CENECA.

1985 Los programas chilenos de TV infantil. Santiago: Corporación de Promoción Universitaria.

GAÍnZA, Violeta

2003 "La educación musical entre dos siglos: del modelo metodológico a los nuevos paradigmas", Serie Documentos de Trabajo. Escuela de Educación. Buenos Aires: Universidad de San Andrés. Disponible en http://repositorio.udesa.edu.ar/jspui/handle/10908/773? mode=full [acceso: 12 de diciembre 2018].

González, Juan Pablo y Claudio Rolle

2009 Historia social de la música popular chilena, 1950-1973. Santiago: Universidad Católica de Chile. 
Graetzer, Guillermo y Antonio Yepes

1961 Introducción a la práctica del Orff-Schulwerk. Buenos Aires: Barry.

Hurtado, María de la Luz et al.

1988 Historia de la televisión chilena entre 1959 y 1973. Santiago: CENECA.

Kock, HermanN

1977 Música para niños. Concepción: Universidad de Concepción.

LAGAZ, JORGE

2014 "Mazapán: Nunca hemos hecho propaganda ni comerciales, no nos interesan esos valores", Mutis.cl. www.mutis.cl/entrevistas/mazapan- nunca-hemos- hecho-propaganda-ni-comerciales-no-nos-interesan-esos-valores/ [acceso: 12 de septiembre 2014].

López Cano, RubéN

2007 "Música e intertextualidad". Pauta. Cuadernos de teoría y crítica musical, 104, pp. 30-36. Versión online: www.lopezcano.net

Martín Escobar, María Jesús

2001 Las canciones infantiles de transmisión oral en Murcia durante el siglo XX, Murcia: Universidad de Murcia.

Menú a la CARTa

2014 "La historia de Cachureos", Menú a la Carta, Youtube, 15 de mayo. Video. Disponible en www.youtube.com/watch?v=jrIVBVl9Rtg [acceso: 12 de diciembre 2018].

Ministerio de Educación, División de Educación General, Unidad de Educación Parvularia. 2011 Cuadernillo de orientaciones pedagógicas Educación Parvularia. Núcleo de aprendizajes. Lenguajes artísticos. Santiago, Chile: Ministerio de Educación. www.mineduc.cl/usuarios/parvularia/ doc/201204161411230.lenguaj es_artisticos.pdf [acceso: 20 de agosto 2014].

Ministerio de Educación

2012 Bases curriculares. Educación Básica. Música. Santiago, Chile: Ministerio de Educación.

Minks, Amanda

2002 "From Children's Song to Expressive Practices: Old and New Directions in the Ethnomusicological Study of Children”, Ethnomusicology, 46/3, pp. 379-408. University of Illinois Press on behalf of Society for Ethnomusicology. Disponible en www.jstor.org/ stable/852716 [acceso: 12 de diciembre 2018].

OCHOA, ANa María

2003 Músicas locales en tiempos de globalización. Bogotá: Norma.

PARTy, DANiEL

2008 "The Miamization of Latin-American pop music", Postnational musical identities: Cultural Production, Distribution and Consumption in Globalized Scenario, editado por Ignacio Corona y Alejandro Madrid, Lanham, MD: Lexington Books, pp. 65-80.

Pérez Ortega, JuAn

1974 Música folklórica y popular infantil chilena. Ediciones Universitarias de Valparaíso.

Ponce, DAVID

2013 “Aparato Raro, la reunión”, Emol.com, 26 de junio. www.lamusica.emol.com/detalle/index. asp?idnoticia=605794 [acceso: 2 de octubre 2014].

Poveda, Juan Carlos

2013 "Infancia y televisión en los ochenta. Reflexiones a partir de la relevancia de Mazapán en el imaginario de la nostalgia”. Ponencia presentada en el VII Congreso Chileno de Musicología "Viejas y nuevas ortodoxas. Ideas en movimiento en la historiografía musical actual", 16 al 19 de enero, en Concepción, Chile. 
Ramírez, PAul

2007 "Concepciones de infancia. Una mirada a las concepciones de infancia y su concreción en las prácticas pedagógicas de un grupo de profesionales de la educación. Tesis para optar al título de Profesor en Educación Básica y al grado de Licenciado en Educación”. Disponible en http://bibliotecadigital.academia.cl/handle/123456789/413 [acceso: 12 de diciembre 2018].

ROJAS, JORGE

2010 Historia de la infancia en el Chile Republicano. 1810-2010 [Versión online]. Junta Nacional de Jardines Infantiles. Disponible en https://www.aacademica.org/jorge.rojas.flores/9.pdf [Consultado 12 de diciembre 2018]Rojas, Jorge y Gonzalo Rojas.

2008 “Auditores, lectores, televidentes y espectadores. Chile mediatizado. 1973-1990”, Historia de la vida privada en Chile. El Chile contemporáneo. De 1925 hasta nuestros días, editado por Rafael Sagredo y Cristián Gazmuri. Santiago: Aguilar Chilena, pp. 381-422.

SAnuy, Monserrat y Luciano GonzÁlez Sarmiento

1963 Orff-Schulwerk. Música para niños. Introducción. Madrid: Unión Musical Española.

Scaruffi, Piero

2005 "The New Wave of Pop and Synth-pop", A History of Rock and Dance Music. Disponible en www.scaruffi.com/history/cpt411.pdf [acceso: 12 de diciembre 2018].

UNICEF. Fondo de las NACIONES UnidAS PARA LA INFANCIA

2012 IV foro de desarrollo infantil: Los beneficios de la experiencia musical en los niños. Disponible en http://unicef.cl/web/iv-foro-de-desarrollo-infantil-los-beneficios-de-la-experiencia-musicalde-los-ninos-3/ [acceso: 12 de diciembre 2018].

Vélez Flórez, Luz DANelly

2013 "La música cuenta: sentidos y significados de la canción popular-tradicional infantil en contexto del Instituto Popular de Cultura de Cali”. Trabajo de grado para optar al título de Magíster en Educación: Desarrollo humano, Universidad de San Buenaventura.

Voz Ciudadana

2014 “Mazapán: Entrevista en Una Belleza Nueva", Voz Ciudadana, 6 de abril. Video. http://vozciudadanachile.cl/mazapan-entrevista-en-una-belleza-nueva- 2/ [acceso: 29 de septiembre 2014].

Watson, Stella M.

2011 "La canción infantil tradicional. Eje de proyectos interdisciplinarios", Pasado, presente y futuro de la cultura popular: Actas del IV Congreso de la SELICUP, coordinadas por Patricia Bastida et al. Palma de Mallorca: s. d.

\section{DISCOGRAFÍA Y VIDEOS DE MÚSICA}

Balá, Carlos, Dante Gilardoni y Filinto Rebecchi

1977 El profesor distraído [Grabada por Carlitos Balá]. En ¿ Y qué gusto tiene la sal? [LP]. Argentina: Microfon.

Balá, Carlos, Dante Gilardoni y Filinto Rebecchi

1977 El profesor distraído [Grabada por Cachureos (Marcelo Hernández)]. En Cachureos 88 [Casete]. Santiago: Aries (1988).

Cachureos

2016 Cachureos Lollapalooza-Kidzapalooza.

2016 Youtube, 3 de agosto 2016. Video. Disponible en https:/ /www.youtube.com/watch?v= hpeDjD6Bjb0 [acceso: 13 de diciembre 2018]. 
Cachureos 88

2010 El Profesor Distraído. Youtube, 31 de octubre. Video. Diponible en www.youtube.com/ watch?v=d-oeJaaCZRM [acceso: 12 de diciembre 2018].

Carlitos Balá

2010 El Profesor Distraído. Youtube, 9 de enero 2010. Video. Disponible en www.youtube.com/ watch?v=3EledSHOJFc [acceso: 12 de diciembre 2018].

LAVANChy, CARMEN

1981 La vaquita loca [Grabada por Mazapán]. En Canciones infantiles y Cuento de Navidad [CD]. Santiago: SYM.

MARCELO

2011 Mundo feliz. Youtube, 23 de septiembre. Video. Disponible en www.youtube.com/ watch?v=FDRsut01SbY [acceso: 12 de diciembre 2018].

MAZAPÁN

2017 La Vaquita Loca. Youtube, 6 de mayo. Video. Disponible en https://www.youtube.com/ watch?v=Imt3HF5EZoc [acceso: 13 de diciembre 2018].

Miriam HERnÁNDEZ

1989 Ay amor-Clip. Youtube, 9 de marzo 2012. Video. Disponible en www.youtube.com/watch?v= f5Y6rACkXA [acceso: 12 de diciembre 2018].

OrfF, CarL

1966 Vier Stücke Für Xylophon. Allegretto, für Sopran-, Altxylophon, Maracas, Schellentrommel und Tom-Toms [Grabada por Karl Peinkofer Percussion Ensemble]. En Orff-Schulwerk, Vol. 1: Musica Poetica [CD]. Tucson, Arizona: Celestial Harmonies (1995).

Palito Ortega

2011. Bienvenido amor (canción con letra). Youtube, 24 de septiembre. Video. Disponible en www. youtube.com/watch?v=TEkymiIJhY0 [acceso: 12 de diciembre 2018].

Palito Ortega

2011 La Felicidad (Video Original). Youtube, 6 de mayo. Video. Disponible en www.youtube.com/ watch?v=Ivu9LBIHoh8 [acceso: 12 de diciembre 2018]. 